\title{
Advanced Imaging Technology in Biliary Tract Diseases: Narrow-Band Imaging of the Bile Duct
}

\author{
Hyun Jong Choi, Jong Ho Moon and Yun Nah Lee \\ Digestive Disease Center and Research Institute, Department of Internal Medicine, Soonchunhyang University School of Medicine, \\ Bucheon, Korea
}

Newly introduced direct peroral cholangioscopy and the development of video choledochoscopes have enabled more defined observation of bile duct mucosal lesions with clearer images. Narrow-band imaging (NBI) is a unique endoscopic imaging technology that provides enhanced endoscopic images of surface mucosal structures and its superficial microvessels. Advanced cholangioscopy and NBI are expected to be useful for precise evaluation and correct diagnosis of biliary tract diseases. However, the diagnostic value of advanced bile duct imaging with cholangioscopy requires further evaluation. Clin Endosc 2015;48:498-502

Key Words: Cholangioscopy; Peroral cholangioscopy; Narrow-band imaging; Image-enhanced endoscopy

\section{INTRODUCTION}

Image-enhanced endoscopic technologies, including narrow-band imaging (NBI) with magnification have been restrictively applied for evaluation of the bile duct. Thus, there are only limited data on the role of image-enhanced endoscopy in assessing bile duct mucosal lesions. However, the development of video choledochoscopes and the recent advances in cholangioscopy systems have permitted expanded performance of cholangioscopy and enhanced endoscopic evaluation of mucosal surface characteristics of biliary tract diseases. In this review, we present the recent advances in cholangioscopy systems and the current status of image-enhanced endoscopy for the evaluation of biliary tract diseases, particularly focusing on NBI cholangioscopy.

Received: October 9, 2015 Revised: November 4, 2015

Accepted: November 4, 2015

Correspondence: Jong Ho Moon

Digestive Disease Center and Research Institute, Soonchunhyang University Bucheon Hospital, Soonchunhyang University School of Medicine, 170 Jomaru-ro, Wonmi-gu, Bucheon 14584, Korea

Tel: +82-32-621-5094, Fax: +82-32-621-5080, E-mail: jhmoon@schmc.ac.kr

(c) This is an Open Access article distributed under the terms of the Creative Commons Attribution Non-Commercial License (http://creativecommons.org/ licenses/by-nc/3.0) which permits unrestricted non-commercial use, distribution, and reproduction in any medium, provided the original work is properly cited.

\section{RECENT DEVELOPMENTS IN CHOLANGIOSCOPY SYSTEMS}

There are recent advancements in cholangioscopic systems for overcoming limitations of the conventional mother-baby endoscope system. One of the newly developed peroral cholangioscopy (POC) systems is the SpyGlass Direct Visualization System (Boston Scientific, Natick, MA, USA). This is a catheter-based, single-operator POC system that introduces four-way steering SpyScope (10 Fr outer diameter) with SpyGlass (a fiber optic device of $0.9 \mathrm{~mm}$ diameter with 6,000-pixel resolution power) through the working channel of therapeutic duodenoscope. The SpyGlass POC system has opened a new horizon in the cholangioscopic evaluation of biliary tract diseases. However, the image quality is not satisfactory for precise evaluation of bile duct lesions. In addition, image-enhanced endoscopy such as NBI is not available with this system.

Another newly introduced POC system is the direct POC using an ultraslim upper endoscope, which is directly inserted into the bile duct through the duodenal papilla. ${ }^{1-4}$ This method uses the most widely available conventional endoscopy system. It provides good endoscopic visualization with the highest resolution among the current cholangioscopy systems. Direct POC also enables image-enhanced endoscopy such as 

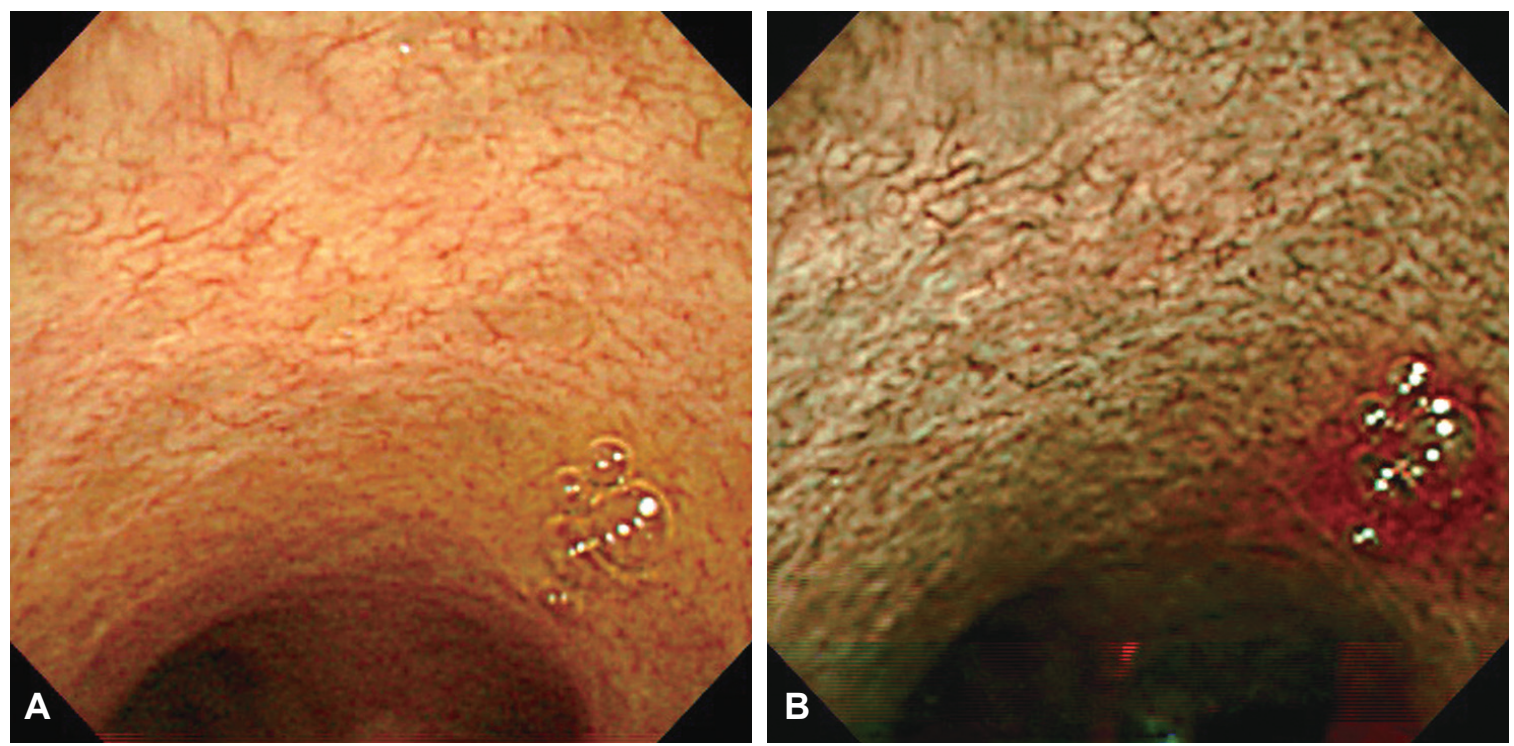

Fig. 1. Cholangioscopic view of a normal bile duct. (A) White light image. (B) Narrow-band imaging (NBI). Note how fine reticular superficial microvessels become more prominent with $\mathrm{NBI}$.

NBI. However, insertion of a slim endoscope into the bile duct requires additional assisting accessories and some maneuvering skills because of the acute angle between the duodenum and the bile duct. Furthermore, direct POC is usually indicated in patients with dilated bile duct ( $>8 \mathrm{~mm}$ in diameter). Improvement of additional assisting accessories and development of multibending slim endoscope are expected to enable easier performance of direct POC. ${ }^{5-7}$

\section{CHOLANGIOSCOPIC EVALUATION FOR BILIARY TRACT DISEASES}

Cholangioscopic findings for biliary tract diseases have been reported in previous PTCS or POC studies. Normal bile duct mucosa is observed as a flat surface, with or without shallow pseudodiverticula ("dimple") and fine networks of thin microvessels (Fig. 1). Benign inflammatory mucosal lesion may be observed as a slightly homogeneous papillogranular surface or scale-like appearance without primary mass suggesting hyperplasia, ulcer or scar change with convergence of folds, or bumpy surface with or without pseudodiverticula (Fig. 2). Cholangioscopic findings suggesting malignant lesion show thick irregular tortuous vessels ("tumor vessels"), irregular papillogranular or fine granular surface, fish-egg like appearance, and mucosal friability with easy oozing of blood (Fig. 3). ${ }^{8-13}$ Cholangioscopic evaluation may improve diagnostic yield to endoscopic retrograde cholangiopancreatography (ERCP)-based evaluation of bile duct lesions and be useful for pre-operative bile duct evaluation of tumor spreading. Osanai et al. ${ }^{12}$ evaluated the diagnostic accuracy of POC (mother-baby endoscope system) in evaluating biliary tract lesions. The diagnostic accuracy, sensitivity, and specificity of POC in comparison with ERCP-guided forceps biopsy for indeterminate biliary diseases $(n=38)$, were $92.1 \%$ vs. $85.7 \%, 96.4 \%$ vs. $81.5 \%$, and $80.0 \%$ vs. $100 \%$, respectively. The accuracy of ERCP, ERCP with POC, and ERCP with POC plus POC-guided biopsy, for the preoperative evaluation of tumor extension $(n=49)$, were $73.5 \%, 83.5$, and $92.9 \%$ respectively.

\section{NARROW-BAND IMAGING FOR BILIARY TRACT DISEASES}

NBI is a unique technology, allowing image-enhanced endoscopy by using a single push button on the light source system. The NBI system is based on the modification of spectral features with an optical color separation filter that eliminates all illumination wavelengths except for two narrow wavelengths, to highlight surface structures and capillaries. ${ }^{14,15}$ NBI provides enhanced visualization of surface mucosal structures and mucosal microvessels compared to conventional white light images. Therefore, NBI may be useful for precise observation and differentiation of bile duct mucosal lesions. Itoi et al. ${ }^{16}$ evaluated the clinical usefulness of video cholangioscopy (mother-baby endoscope POC system) by using NBI in seven patients with bile duct cancer and five patients with benign biliary diseases. Regardless of whether the lesion is benign or malignant, the observation made with NBI was as good as or better than conventional white light observation to identify both the surface structure 
C clinical endoscopy
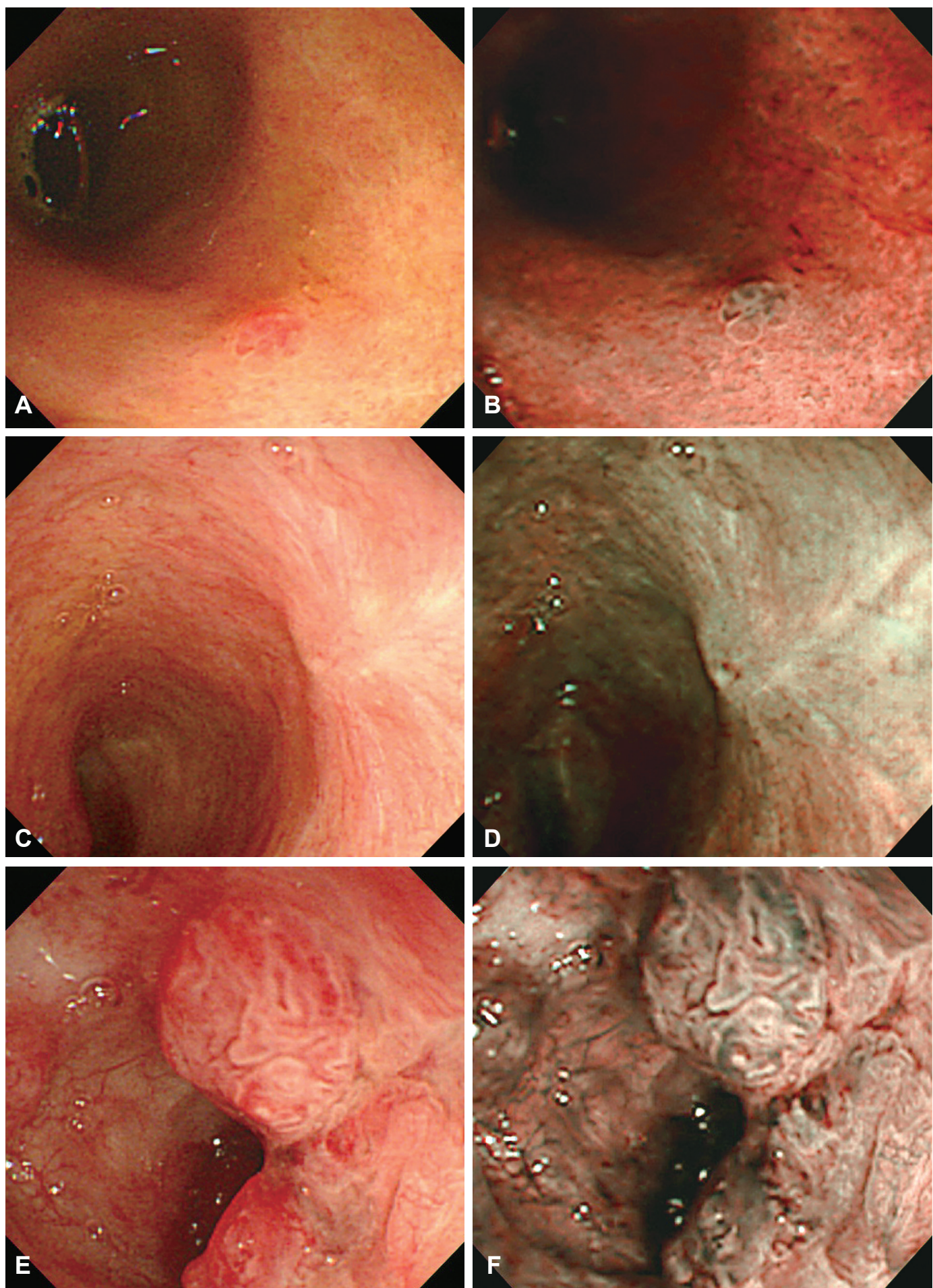

Fig. 2. Cholangioscopic view of benign bile duct lesions with white light images and narrow-band imaging, respectively. (A, B) Inflammatory polyp. (C, D) Scar change. (E, F) Inflammatory lesions.

$(p<0.01)$ and mucosal vessels $(p<0.05)$. In particular, NBI allowed better observation of superficial tumor margin. NBI also detected four lesions that were not identified via conventional white light observation.

\section{LIMITATIONS OF NARROW-BAND IMAGING FOR BILIARY TRACT DISEASES}

There are fundamental and technical limitations in the NBI enhanced cholangioscopy for evaluation of biliary tract 

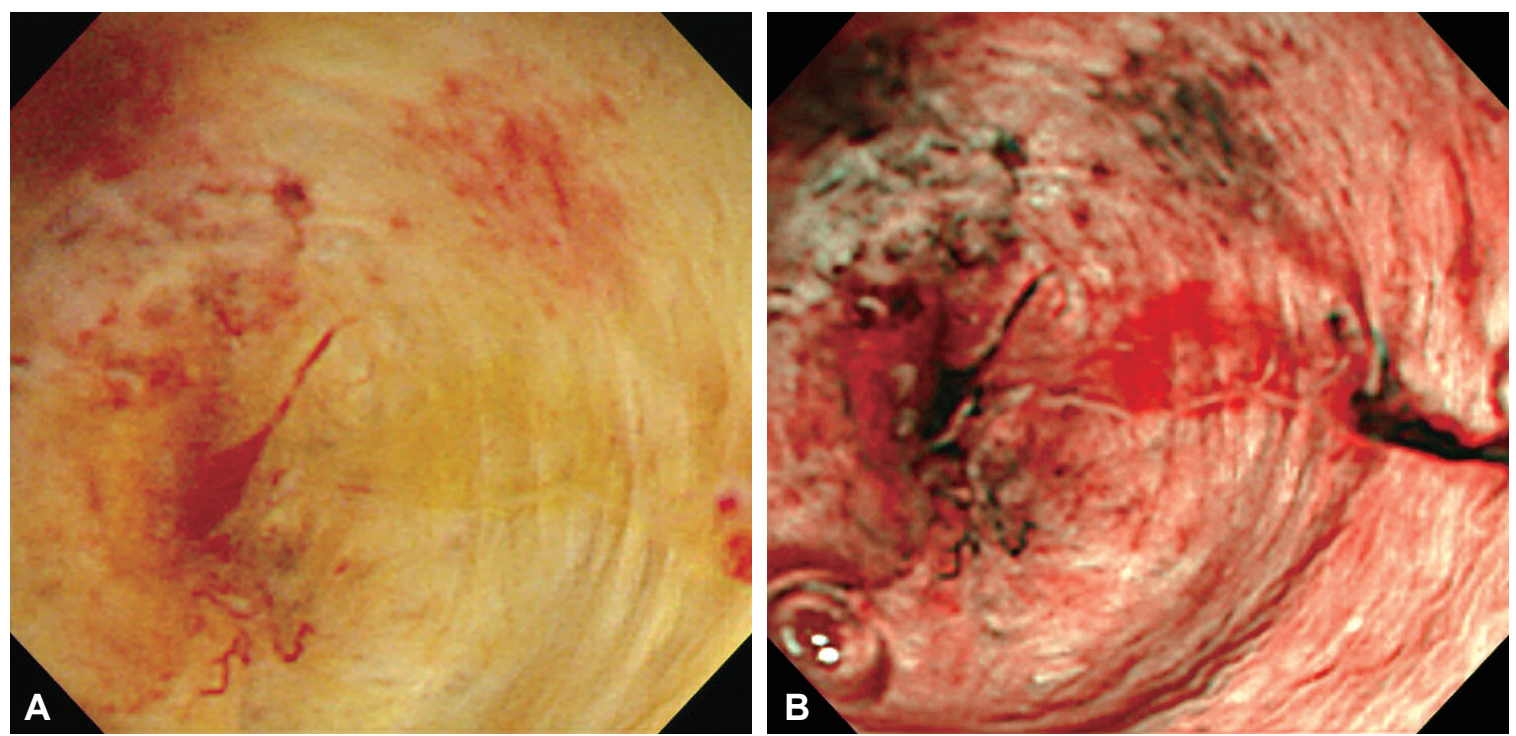

Fig. 3. Cholangioscopic view of malignant biliary structure. (A) White light image. (B) Narrow-band imaging (NBI). Note the thick "tumor vessels" enhanced by NBI.

diseases. First, it is impossible to evaluate submucosal or extraductal conditions with a cholangioscope. Therefore, NBI is only useful for assessing mucosal surface structures of biliary tract lesions. Submucosal spread or extraductal invasion of the tumor cannot be evaluated by cholangioscopy with NBI. Second, bile appears as dark red color and blood as dark color on NBI. Therefore, washing bile and blood during NBI evaluation is required to obtain clear endoscopic view. ${ }^{4,16}$ Third, magnification function is not available in current cholangioscopy systems, unlike endoscopes used in the gastrointestinal tract. Magnifying endoscopy may provide more detailed images of bile duct mucosal structures and be helpful in cholangioscopic NBI evaluation. ${ }^{17}$ In addition, cholangioscopic findings of neoplastic and non-neoplastic biliary tract diseases are not sufficiently established until now and studies that correlate NBI findings with histopathologic findings are lacking. Although cholangioscopic visual diagnosis with NBI has high sensitivity for bile duct mucosal lesions, a definite diagnosis should be confirmed by histopathologic findings. ${ }^{13,15,18}$

\section{CONCLUSIONS}

ERCP-based cholangiographic evaluation with conventional cross-sectional images remains the primary and essential modality for diagnosing biliary tract diseases. Continuous improvement and development of direct cholangioscopic evaluation of the bile duct are ongoing to enhance diagnostic accuracy. The role of cholangioscopy with NBI has not been sufficiently evaluated and has limitations in assessing biliary tract diseases. Nevertheless, with continuous advancement in cholangioscopy and imaging technology, the value of chol- angioscopy and enhanced image technology like NBI for the evaluation of biliary tract diseases is expected to grow in the near future.

\section{Conflicts of Interest}

The authors have no financial conflicts of interest.

\section{REFERENCES}

1. Larghi A, Waxman I. Endoscopic direct cholangioscopy by using an ultra-slim upper endoscope: a feasibility study. Gastrointest Endosc 2006;63:853-857.

2. Choi HJ, Moon JH, Ko BM, et al. Overtube-balloon-assisted direct peroral cholangioscopy by using an ultra-slim upper endoscope (with videos). Gastrointest Endosc 2009;69:935-940.

3. Moon JH, Ko BM, Choi HJ, et al. Intraductal balloon-guided direct peroral cholangioscopy with an ultraslim upper endoscope (with videos). Gastrointest Endosc 2009;70:297-302.

4. Moon JH, Terheggen G, Choi HJ, Neuhaus H. Peroral cholangioscopy: diagnostic and therapeutic applications. Gastroenterology 2013;144:276282.

5. Itoi T, Sofuni A, Itokawa F, et al. Free-hand direct insertion ability into a simulated ex vivo model using a prototype multibending peroral direct cholangioscope (with videos). Gastrointest Endosc 2012;76:454-457.

6. Itoi T, Nageshwar Reddy D, Sofuni A, et al. Clinical evaluation of a prototype multi-bending peroral direct cholangioscope. Dig Endosc 2014;26:100-107.

7. Lee YN, Moon JH, Choi HJ, et al. A newly modified access balloon catheter for direct peroral cholangioscopy by using an ultraslim upper endoscope (with videos). Gastrointest Endosc 2015 Aug 15 [Epub]. http://dx.doi.org/10.1016/j.gie.2015.08.021.

8. Kim HJ, Kim MH, Lee SK, Yoo KS, Seo DW, Min YI. Tumor vessel: a valuable cholangioscopic clue of malignant biliary stricture. Gastrointest Endosc 2000;52:635-638.

9. Seo DW, Lee SK, Yoo KS, et al. Cholangioscopic findings in bile duct tumors. Gastrointest Endosc 2000;52:630-634.

10. Fukuda Y, Tsuyuguchi T, Sakai Y, Tsuchiya S, Saisyo H. Diagnostic utility of peroral cholangioscopy for various bile-duct lesions. Gastrointest Endosc 2005;62:374-382. 
11. Kawakami H, Kuwatani M, Etoh K, et al. Endoscopic retrograde cholangiography versus peroral cholangioscopy to evaluate intraepithelial tumor spread in biliary cancer. Endoscopy 2009;41:959-964.

12. Osanai M, Itoi T, Igarashi $\mathrm{Y}$, et al. Peroral video cholangioscopy to evaluate indeterminate bile duct lesions and preoperative mucosal cancerous extension: a prospective multicenter study. Endoscopy 2013;45:635-642.

13. Nishikawa T, Tsuyuguchi T, Sakai Y, et al. Preoperative assessment of longitudinal extension of cholangiocarcinoma with peroral video-cholangioscopy: a prospective study. Dig Endosc 2014;26:450-457.

14. Itoi T, Neuhaus H, Chen YK. Diagnostic value of image-enhanced video cholangiopancreatoscopy. Gastrointest Endosc Clin N Am 2009;19:557566
15. Ishida Y, Itoi T, Okabe Y. Can image-enhanced cholangioscopy distinguish benign from malignant lesions in the biliary duct? Best Pract Res Clin Gastroenterol 2015;29:611-625.

16. Itoi T, Sofuni A, Itokawa F, et al. Peroral cholangioscopic diagnosis of biliary-tract diseases by using narrow-band imaging (with videos). Gastrointest Endosc 2007;66:730-736.

17. Ishida Y, Okabe Y, Kaji R, et al. Evaluation of magnifying endoscopy using narrow band imaging using ex vivo bile duct (with video). Dig Endosc 2013;25:322-328.

18. Azeem N, Gostout CJ, Knipschield M, Baron TH. Cholangioscopy with narrow-band imaging in patients with primary sclerosing cholangitis undergoing ERCP. Gastrointest Endosc 2014;79:773-779. 